\title{
Analysis of innovation diffusion theory under "micro" environment - Survey analysis of application and promotion of WeChat among the youth group
}

\author{
Chen Wei, Bingqi Wang \& Ran Ma \\ Beijing Institute of Science and Technology Information, Beijing, China
}

\begin{abstract}
Since WeChat has been launched in 2011, as of the first quarter of 2015, the active users have reached 549 million per month ${ }^{1}$. WeChat has become the largest mobile instant messaging software among the user groups in Asia. Therefore, WeChat is no longer "micro", and grabs the attention of more youth groups by virtue of the "micro" advantages in the Internet era in a way of low-priced new media. Through sorting 192 effective questionnaires recovered, this paper summarizes some transmitting tendency and suggestions of "micro" innovation diffusion from the research view of the concept of innovation diffusion theory, and development stage of WeChat in the youth group, based on the survey data and by the use of the statistics of informatics, qualitative and quantitative analysis method, so as to provide a certain theoretical basis for the future research of WeChat.
\end{abstract}

Keywords: WeChat, innovation diffusion, information, transmitting

According to the questionnaire of the situation and impact of using WeChat by the youth group on "Sojump", in 100 questionnaires, WeChat users at the age of 20 to 28 account for $68.97 \%$; most of WeChat users beside account for $82.76 \%$; people who save SMS and telephone charge account for $27.59 \%$; people who surf online for six hours and above per day account for $27.59 \%$.

Therefore, faced with such a huge user group, to carry out education of the youth group and learning practice by the use of the innovation diffusion theory will be an effective communication theory to transform knowledge innovation into social benefits in a long period of future.

\section{THEORETICAL BASIS}

The invention and diffusion of new matters will be accepted or rejected by people, and will produce a certain result, resulting in the future development of

${ }^{1}$ Tencent released 2015 WeChat user data report [C] Netease.http://digi.163.com/15/0601/06/AR0MPOGT00162OU T.html

${ }^{2}$ Sojump: http://www.sojump.com/ social changes. In the social process of the innovation diffusion, it is comprised by four parts: innovation, communication channels, social systems and events.

\subsection{Innovation diffusion theory}

The innovation diffusion theory is one of the classical theories in the research of the communication effect, proposed by an American scholar, E.M.Rogers in the 1960 s, which is a theory to persuade people to accept the theory of new concept, new matter and new products, and focuses on the impact of mass media on society and culture ${ }^{3}$.

In the process of innovation diffusion, Rogers believes that, the selection of new knowledge and new technology is divided into several stages, namely the cognitive stage, persuasion stage, decision stage, implementation stage and confirmation stage 4 .

\footnotetext{
${ }^{3}$ Zhou, Zhi. 2008. Research on the innovation and diffusion theory and its enlightenment to advertising communication strategy. Southeast Communication, (11).

${ }^{4}[$ US]. E.M. Roggers. 2002. Diffusion of Innovations. Xin Xin (translated by). Beijing: Central Compilation \& Translation Press.
} 


\subsection{Promotion and application of WeChat meeting requirements of the innovation diffusion theory}

In 2011, successful promotion of WeChat almost covers all main elements of innovation diffusion, for example, point-to-point precision push, flexible and diverse forms of communication, opportunities of strong relationship, high-frequency information output, multi-mode text mode, economic and convenient interactive mode and so on. As a new type of IM tool, WeChat communicates between social members or organizations through one or several channels. This process is gradually adopted by other potential users, that is, the process of gradually diffusing $\mathrm{WeChat}$ to every corner of the social system since its birth and eventually adopted by the users.

According to the speed of accepting new matters, Rogers divides the adopters into five categories: innovators, early adopters, mid-term adopters, late adopters and laggards. In the spreading and diffusion of the new concept, the innovators and early adopters undoubtedly popularize and erect a good example for the innovative matters, and play a leading and exemplary role, because they are not only able to accept the initial limitations of new products, and often make other members in the group believe and adopt new matters through their influence.

In summary, in the diffusion of WeChat, there are many young innovators and early adopters in the generation after $80 \mathrm{~s}$ and $90 \mathrm{~s}$, so the promotion and application of WeChat in the youth group is also more in line with the mode of the innovation diffusion theory.

\subsection{Research methods}

The research adopts the questionnaires, statistics, quantitative and qualitative methods and other methods.

$>$ Time of questionnaire survey: January to April 2015;

$>$ Respondents: 22 to 34-year-old young male and female in Beijing Institute of Science and Tech- nology Information, of which 24 to 27 -year-old young male and female account for $95.45 \%$, while 28 to 34 -year-old young male and female account for $4.55 \%$;

$>$ Way to distribute questionnaire: randomly distribution. 200 questionnaires are distributed, and 192 valid questionnaires are recovered.

\begin{tabular}{llll}
\hline & Frequency & Percent & Valid Percent \\
\hline Male & 115 & $60 \%$ & $60 \%$ \\
Female & 77 & $40 \%$ & $40 \%$ \\
Total & 192 & $100 \%$ & $100 \%$ \\
\hline
\end{tabular}

The questionnaire survey is in line with the requirements of data available for analysis, and has a certain research value.

\section{RESEARCH FINDING}

Among the respondents, $52.5 \%$ of youth groups open the mobile phone to immediately login WeChat; $32.5 \%$ of youth groups update circle of friends anytime, anywhere; $60 \%$ of youth groups know about the situation of friends through WeChat. Thus, the phenomenon of using WeChat in the youth groups is very common.

\subsection{Cognitive stage}

According to the statistics of questionnaire (see Figure 1), $80 \%$ of youth groups contact WeChat through the network at early stage; $11 \%$ through the traditional media, and $9 \%$ through the communication between colleagues or friends. Thus, the mass media is the main channel of learning knowledge. It also proves the theory of "mass communication channel playing a greater role than interpersonal communication channel" mentioned in the innovation diffusion theory.

To sum up, at this stage, WeChat has two characteristics of the innovation diffusion theory: the first is the relative advantage. The users can learn about

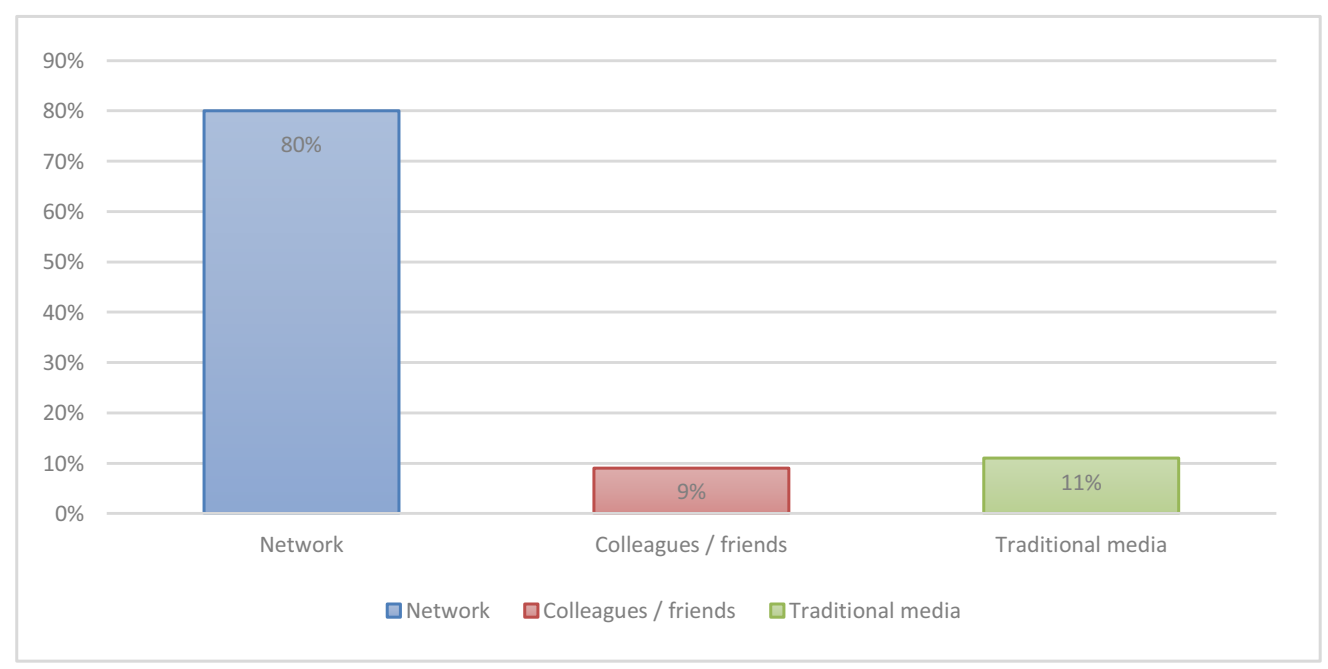

Figure 1. Diagram of understanding channels 


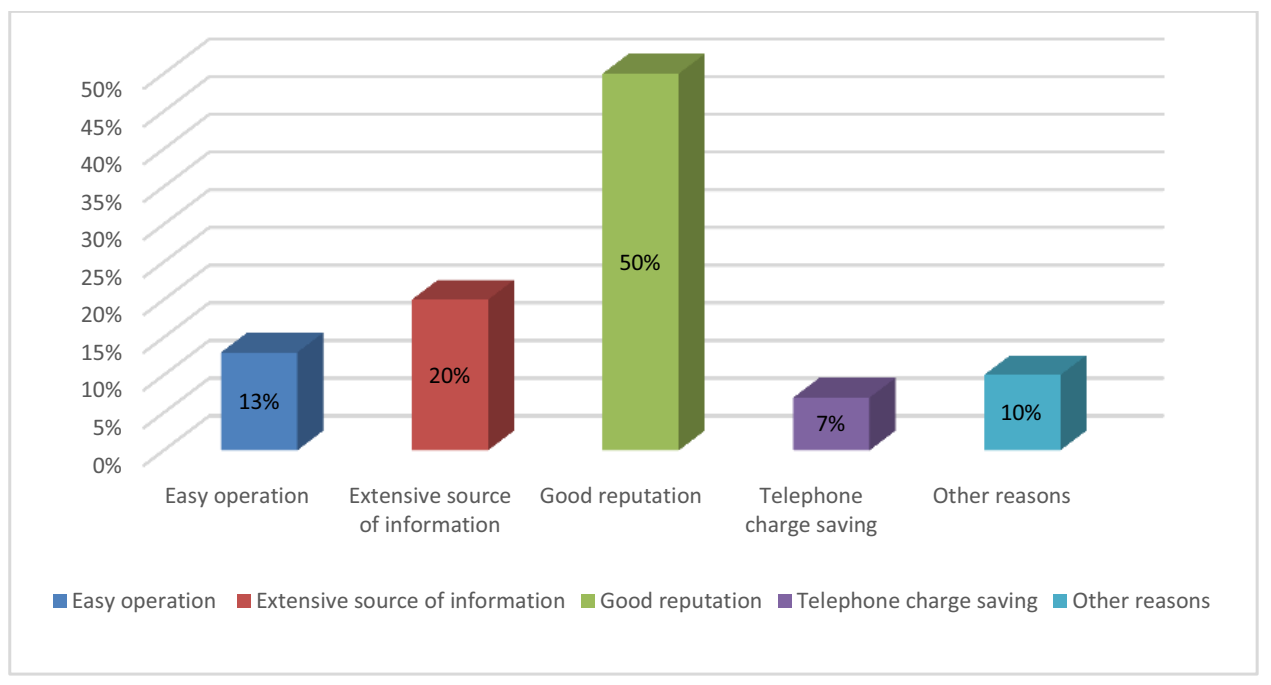

Figure 2. Main reasons for the youth groups to use WeChat

WeChat through multi-channels and accurately push information to different receiving users. WeChat has multimedia features, which can publish texts, images, voice, video and many other kinds of information, and focus on interaction and feedback. In the process of adopting innovation by people, the factor affecting people to adopt innovation is the cognitive degree of its advantage, rather than its huge advantages. The second is the complexity of the feature. The research shows that, several innovations can be easily understood by most members of the social system, but some innovations are more responsible, and adopted slowly. The smaller the complexity of innovation is, the easier to be understood by people, and the greater the speed of adoption is. WeChat has such a feature, which can make exchange more convenient after clicking gently.

\subsection{Persuasion stage}

Through the statistical analysis of the questionnaire (see Figure 2), at the persuasion stage, the reasons for the respondents to decide to use WeChat are as follows: good reputation, extensive source of information, easy operation and telephone charge saving. The above four reasons respectively account for $50 \%, 20 \%$, $13 \%$ and $7 \%$.

In conclusion, this data confirms the viewpoint of Rogers. The early adopters are willing to take the lead in accepting and using innovative matters and willing to take adventure. These people not only have a strong endurance for various deficiencies in the initial period of innovation, but also "persuade" the opinion leaders in their group, so as to accept and adopt innovative products. It also confirms that the interpersonal channel plays a more important role in persuading people to accept the usage stage.

\subsection{Decision stage}

Among the youth groups surveyed (see Figure 3), 57\% of youth groups often use WeChat; $22 \%$ of the total number occasionally use WeChat; $7 \%$ use WeChat every day; only $3 \%$ do not use it. Thus, WeChat has an absolute advantage among the groups surveyed, and the youth group has obvious manifestations in the curiosity of new matters and enthusiasm of acceptance.

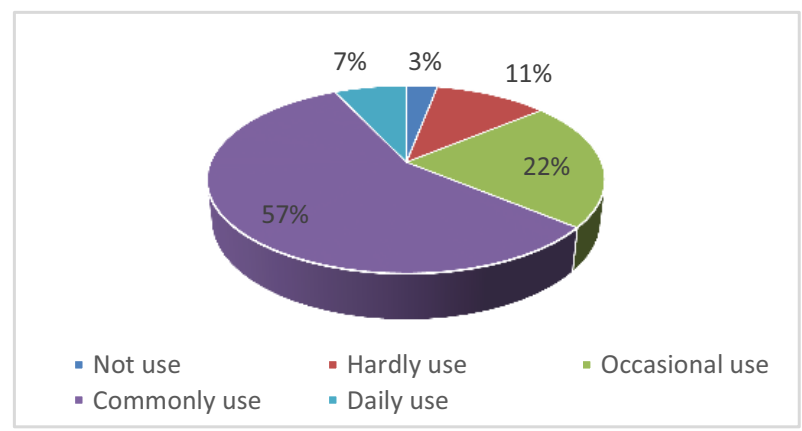

Figure 3 Analysis chart of the usage degree of WeChat

Through the interview with 20 young men and women in 192 questionnaires recovered, "whether the use of WeChat is beneficial, what kind of information is required through WeChat?" Statistical results are as follows:

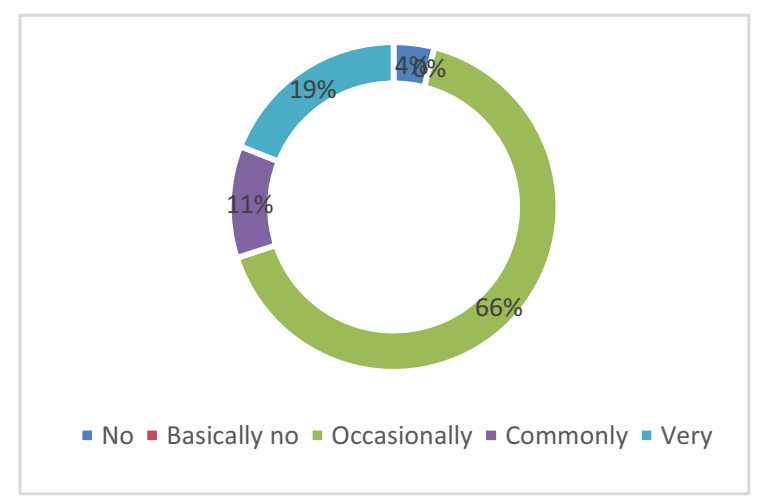

Figure 4. Statistical diagram of whether WeChat is beneficial 
Figure 4 shows that, $66 \%$ of the groups feel occasionally that $\mathrm{WeChat}$ is beneficial, and the proportion has obvious advantages; $19 \%$ of the groups believe that $\mathrm{WeChat}$ is very useful; $11 \%$ of the groups express that WeChat often bring their own useful information; $4 \%$ of the groups do not believe that WeChat can bring any useful information.

Figure 5 shows, $61.29 \%$ of the groups are attracted by the entertainment information; $15.94 \%$ of the groups acquire the information of the current events; 7\% of the groups learn knowledge via WeChat; $5 \%$ of the groups understand the business information through WeChat. Thus, WeChat can meet various needs of the individual preferences, but mainly entertainment.

In summary, the basis for the youth group to determine to use WeChat is because of their own needs, and relying on high compatibility of WeChat, flow economy, good experience of voice chat and other functions, so that the users are willing and decide to use WeChat.

\subsection{Implementation stage}

In terms of the duration of using WeChat (see Figure 6), $37 \%$ of users use it for more than 15 minutes; $22 \%$ of users use it for more than 30 minutes; $34 \%$ of users use it for 6 to 15 minutes; $29 \%$ of users use it for less than five minutes.

There is a majority of people who use it for more than 15 minutes, but the usage duration is basically within 5minutes, or 6 to 15 minutes. WeChat is a main daily communication tool in the surveyed groups, but the emerging communication way of WeChat is still in the growth stage, so the degree of adhesion is to be improved.

Combined with Figures 3 and 4, in terms of the daily operating frequency of $\mathrm{WeChat}$, it is also quite high. $57 \%$ of the groups regularly use it, $22 \%$ of the groups use it once or above per day. It indicates that, the frequency of using WeChat by the youth groups is very high within a certain range, but there is a possi-

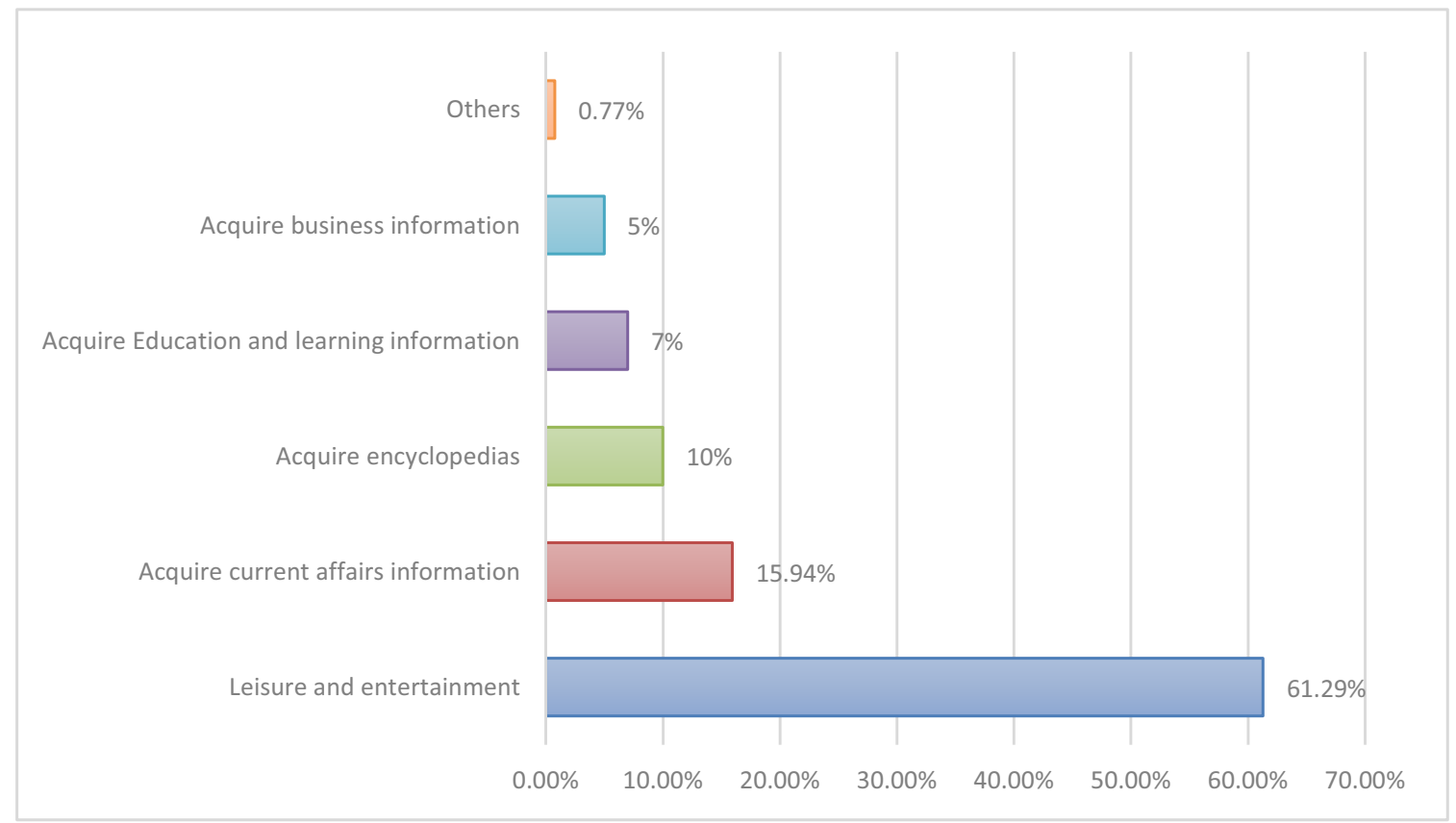

Figure 5. Statistical diagram of reasons for concerning WeChat

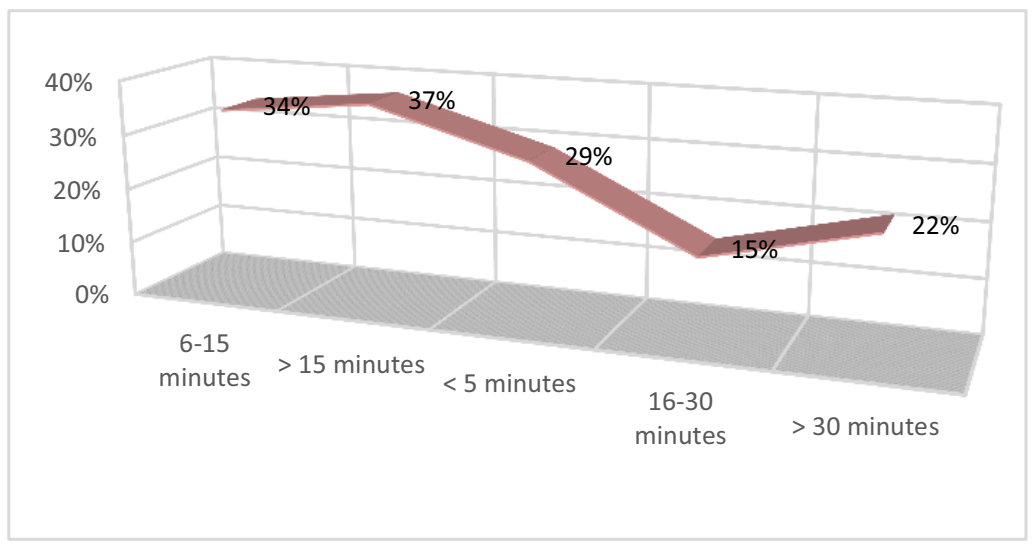

Figure 6. Analysis chart of duration of using WeChat by users 


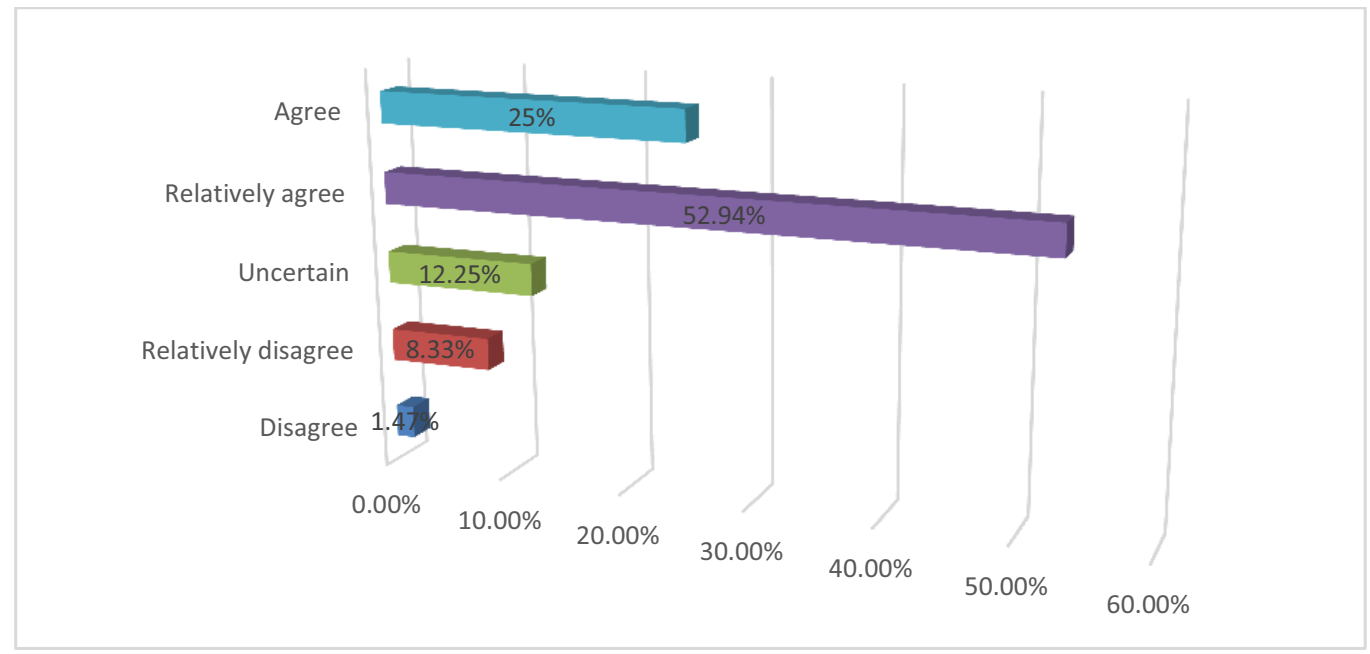

Figure7. Proportion diagram of whether like to use WeChat

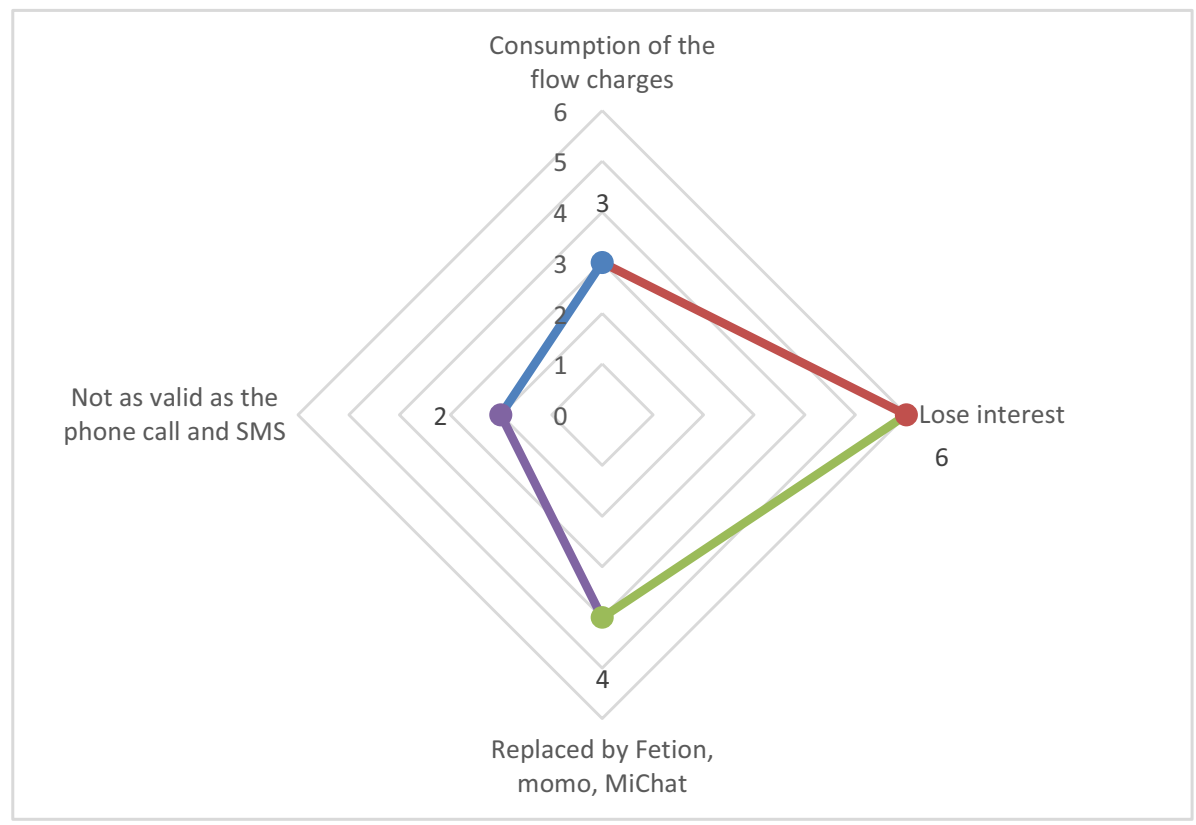

Figure 8. Radar map of factors affecting the use of WeChat

bility of using other new media.

\subsection{Confirmation stage}

The results of the questionnaire survey of "I like to use WeChat" to measure the willingness to use are as follows.

Figure 7 shows that, $52.94 \%$ of the groups prefer to use WeChat, $25 \%$ of the groups like to use WeChat very much; $1.47 \%$ of the groups do not like to use WeChat at all; $12.25 \%$ of the groups do not know. For the existing "dissimilar" opinions in the questionnaire, 15 young men and women are randomly selected to analyze the factors affecting the individuals to use "WeChat" through interviews and communication.

Viewing from the comprehensive analysis, four people are affected other products and abandon the use of WeChat; six people lose their continued attrac- tion for WeChat, with a total of ten people in the groups, accounting for two-thirds of the respondents.

Thus, as emerging communication software, WeChat still has varying degrees of defects at many levels. Meanwhile, it proves that the most important thing for the user groups at the stage of determining continuous use is the innovation of the ability to attract users. After using the innovative products at the initial stage, the users may have a lot of maladjustment. If there are not enough follow-up services and adhesion to absorb, the users will be lost. At the same time, the users will be diverted away from other similar products with competition.

\subsection{Respondents' overall evaluation on WeChat}

The respondents' evaluation on WeChat (see Figure 9): $48 \%$ of the respondents feel that it is "general"; $35 \%$ 
of the respondents feel that it is "relatively satisfactory"; $10 \%$ of the respondents feel that it is "unsatisfactory"; $7 \%$ of the respondents feel that it is "not satisfactory". Thus, the respondents' satisfaction for WeChat is to be further improved. Therefore, to strengthen the market research and interviews of the users and improve the products specifically is conducive to maintaining the market share and future development.

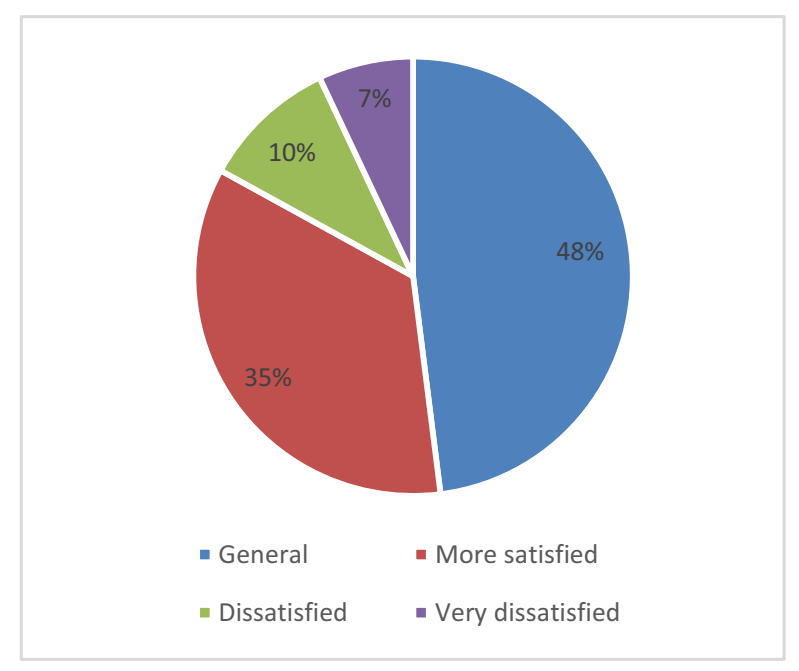

Figure 9. WeChat evaluation map

\section{CONCLUSION AND SUGGESTIONS}

The diffusion of WeChat between users since its birth is in line with the innovation diffusion theory proposed by Rogers. WeChat is first used by a small portion of innovators, so the initial development will be relatively slow. However, with the follow-up of the followers, and increase of the users, it will enter into a golden period of the development, and eventually be accepted by the market and users. Its development process is in line with a curve graph of the innovation diffusion. However, we should also clearly see the key points of the development at each stage and the development trend curve.

\subsection{Research conclusions}

\subsubsection{Cognitive stage will be promoted effectively by the use of the interpersonal communication means of WeChat}

The user groups of WeChat become younger in average age, mainly because of its interpersonal communication services. According to the statistics data of Baidu, young people at the age of 20 to 29 are dominated in the groups of WeChat, of which young people with bachelor degree or above have become a mainstream $^{5}$. WeChat can also set up a list of more stable

${ }^{5}$ Wang, Liyan \& Zhang, Julan. 2013. WeChat meets the demands of interpersonal communication, Economic Vision. relations through the address book of people, so that the breadth and depth of interpersonal communication content will be more considerable.

Based on the above conclusions, combined with the using features of the youth groups, there is a need to pay special attention to the network communication of WeChat, such as the increase of publicity, implementation of WeChat platform and so on. Reliable groups of WeChat can be trained by means of interpersonal communication, in order to affect others to use it through the interpersonal communication. More groups are allowed to contact WeChat at the cognitive stage.

\subsubsection{Persuasion and decision stage should grasp the interpersonal communication channels}

First, the diversification of subscription mode, precision push of information, higher quality of information output, text mode of multimedia features, adequate interaction and feedback reflect the comparative advantages of WeChat;

Second, WeChat can not only meet the needs of a variety of youth groups, but also can be in line with their basic values;

Third, the innovation is inversely proportional to its adoption, so that the simple and straightforward innovation diffusion speed becomes faster;

Fourth, the user is free of any losses after using, who promotes the diffusion of WeChat, and effectively eliminates the risk of perception;

Fifth, many youth groups understand more information with breadth and depth through WeChat, and the "innovation results" acquired are obvious. Since the birth of WeChat, no matter via the media report or interpersonal communication, it arouses a wide concern of the society, especially youth groups.

Therefore, as the object of innovation, it shall also develop potential users at this stage, and adopt a variety of ways to stimulate the user groups to understand the characteristics of WeChat. The comparative advantage, compatibility, complexity, testability and observability of the diffusion innovation theory of WeChat can be used to drive the interpersonal communication function.

\subsubsection{Determination stage should strengthen contin- uous innovation of WeChat}

WeChat has gradually replaced "old" media, such as QQ, micro-blog and so on, and become an important means of communication of a majority of people, especially youth groups. However, new functions of WeChat, such as "Shake It Up Touch", "Floating Bottle", "Auto Racing", "Didi taxi" and so on still could not get rid of being copied by other competitors or replaced by a better procedure, causing the user's beauty fatigue.

According to the statistical results of the interviews with some respondents, $93.51 \%$ of the youth groups use WeChat for "voice chat"; $51.52 \%$ view people 
nearby; $61.66 \%$ view photos in the "circle of friends"; $51.93 \%$ receive offline messages of QQ. However, these functions are also available for the user groups in QQ, momo, MiChat, MicroTalk and other media. Thus, in order to obtain sustained attention, any new matters should not only adapt to multi-faceted needs of users, but also continuously improve and innovate the feedback suggestions and demand for use of the current user groups.

\subsection{Development recommendations}

\subsubsection{Humane care of WeChat}

According to the survey of the ideas of Chinese and American netizens, "nearly $75 \%$ of Chinese netizens think that they can do anything on the network, and say what they could not in reality. However, this figure is only less than $32 \%$ in the United States" 6 . Thus, the management of $\mathrm{WeChat}$ directly affects the quality of the project development. Due to a low threshold of WeChat, negligent management of the content review and other issues, we must have the regulatory responsibility, and truly boycott some topics with negative energy.

\subsubsection{Avoidance of homogenization}

According to the "media compensation theory", the premise for the users to select a media is to compensate for insufficiency of the former media. If its characteristics are not prominent in the innovation, it will lose advantages in the competition. As "momo", "MiChat" and other software on the market, the functions are very similar to that of WeChat. Currently, WeChat has bigger advantages in the competition, but it shall also continue to be innovated, push out new functions, highlight its characteristics and avoid homogenization, and maintain its advantages.

\footnotetext{
${ }^{6}$ The comparison of conception between Chinese and American netizen $[\mathrm{EB} / \mathrm{OL}]$. http://www.baidu.com/link?url=ZcSN4OjLwjDEs8c3346nB MQNUgSkvfVAzz1htRkieVwppjPPMH8SbjnUovG3sJo7uA -S6_GZDV7tle1ThjSB9a7lz7TQPsSOf-8MczMYira\&wd=\& eqi $\overline{\mathrm{d}}=$ eca42ff60000218300000003565fd049
}

\section{ACKNOWLEDGEMENT}

This paper is supported by the project of The Research and Development of Web Public Feelings Analysis Technique of Public Safety Events Based on ISO3 1000 .

\section{REFERENCES}

[1] Mahajan V, Schoeman M E F. 1977. Generalized model for the time pattern of the diffusion process. IEEE Transactions on Engineering Management, (01): 12-18.

[2] Bass F M. 1969. A new-product growth model for consumer durables. Management Science, (05): 215-227.

[3] Hu Zhineng, Xu Jiuping. 2005. Multi-stage dynamical model of innovation product diffusion. Systems Engineering Theory and Practice, 4.

[4] Xie Liqun, Yan Qinghua, Chen Ying. 2011. Viewing exchange dilemma from the "onlooker model" -- Atlas analysis of micro-blog social network. Chinese Media Technology, 8.

[5] Cai Zhiguo. 2013. "Onlooker" is also a force. Voice and Screen World, 1

[6] Yu Jing, Li Junyi. 2013. Spatial-temporal dispersion model of micro-blog marketing information--A case study of Qujiang cultural tourism. Economic Geography, 33.

[7] Wang Qian, Li Ming. 2014. Empirical survey of diffusion of micro-blog comment in China Youth Daily, San Francisco Flower Fall. Journalism Knowledge, 1.

[8] Zhang Meimei. 2014. Chinese Policy Innovation Diffusion - Comparative Case Study Based on Causal Mechanism. Southwest University of Political Science and Law, 3.

[9] Zhang Chengliang. 2014. Analysis of transformation of publishing thought of innovation based on the innovation diffusion theory. Publishing Research, 11.

[10] Zhou Yu. 2011. Communication and social development: perspective of innovation diffusion. Southeast Communication, 8.

[11] Zhang Lei. 2012. Micro-blog wonders under the perspective of the innovation diffusion. Literary Circle, 3

[12] Song Ge. 2015. Academic innovation diffusion process. Journal of Library Science in China, 1. 